\title{
Identification of Common Morphological Lip Patterns in North Indian Population and their Role in Forensic Investigations
}

\author{
${ }^{1}$ Rajeev Chaudhary, ${ }^{2}$ Preet M Singh, ${ }^{3}$ Anupama Mahajan, ${ }^{4}$ Monika Lalit, ${ }^{5}$ Baljit S Khurana
}

\begin{abstract}
Introduction: A series of Forensic odontological studies on lip patterns form an important weapon for personal identification and may constitute a source of circumstantial evidence.Chieloscopy, i.e., study of lip prints which are unique for every individual and remain unchanged forever can be used successfully in the field of forensic science for personal identification. This study was carried out to determine the common lip pattern, their variations in males and females and their role in the identification of an individual in forensic investigations.
\end{abstract}

Materials and methods: The study was conducted on 300 North Indians (150 males and 150 females respectively) the age group of 17-60 in the Department of Forensic Medicine, Shri Guru Ram Das Institute of Medical Sciences and Research, Amritsar. A pencil lipstick of the same color and make was applied with a single motion evenly on the lips. Cardboard bearing a 4"x 10 " strip of thin bond paper was then pressed to the subject's lips, and lip prints were obtained and later studied with the help of a magnifying lens.

Observations and Results: Lip prints were divided into four quadrants and recognized as per Suzuki and Tsuchihashi' classification. Type I (30.33\%) and Type III (35.41\%) were found most prevalent in males and females respectively while Type l' was least prevalent in males $(4.33 \%)$ as well as in females $(0.41 \%)$. The lip patterns remained stable over a period of one year.

Conclusion: Because of unique patterns, the lip prints can be used as an important tool index determination and personal identification in forensic science.

Keywords: Chieloscopy, Forensic investigation, Lip Prints.

How to cite this article: Chaudhary R, Singh PM, Mahajan A, Lalit M, Khurana BS. Identification of Common Morphological Lip Patterns in North Indian Population and their Role in Forensic Investigations. Curr Trends Diagn Treat 2018;2(1):28-31.

\footnotetext{
${ }^{1,4}$ Associate Professor, ${ }^{2}$ Registrar, ${ }^{3,5}$ Professor and Head

1,2,5 Department of Forensic, Sri Guru Ram Das Institute of Medical Sciences \& Research, (SGRDIMSAR), Amritsar, Punjab, India

${ }^{3,4}$ Department of Anatomy, Sri Guru Ram Das Institute of Medical Sciences and Research, Amritsar, Punjab, India
}

Corresponding Author: Rajeev Chaudhary, Associate Professor, Department of Forensic, Sri Guru Ram Das Institute of Medical Sciences and Research, Amritsar, Punjab, India, Mobile: 9501726435, e-mail: crajeev0911@gmail.com

\section{Source of support: Nil \\ Conflict of interest: None}

\section{INTRODUCTION}

For the positive identification of a person in criminal and forensic practices, besides finger prints, DNA and dental records, 'human lip recognition' also known as cheiloscopy can be used in distinguishing the individuals and its presence at the scene of the crime. ${ }^{1,2}$ The wrinkles and grooves on labial mucosa called as sulci labiorum form a characteristic pattern called as lip prints. ${ }^{3,4}$ Anthropologist R.S. Fischer was the first who noted furrows on the red part of human lips in 1902 without suggesting a practical use for the biological phenomenon of the system of furrows. Suzuki and Tsuchihashi ${ }^{5}$ were the first to classify the different patterns present on the human lips in both sexes. The lip patterns can be identified as early as the 6th week of intrauterine life. ${ }^{6}$ The lip prints are unique to a person except in monozygotic twins. ${ }^{7}$ The oily and moist secretions from sebaceous and salivary glands present at the vermillion border enable the formation of a latent lip print whenever there is contact. ${ }^{8}$ At the crime scene (murder, rape, and burglaries) lip prints should be looked on cutlery and crockery items, on windows, door glasses, letters, photographs, cigarette ends, paintings, plastic bags and on food products with tooth marks. The present study was carried out to identify the most common pattern of lip print as it can act as an adjunct for identification as such as well relevant to forensic study in case of criminal investigations.

\section{MATERIALS AND METHODS}

The study was conducted on randomly selected 300 North Indians (150 males and 150 females) for 1 year (2017 to 2018), in the age group of 17 to 60 in the Department of Forensic Medicine, Sri Guru Ram Das Medical College, Amritsar. The individuals who were sensitive to lipstick and having inflammatory lip disease, scars over the lips, malformations, lip deformities, and trauma were excluded from the study. A written informed consent was taken from all the individuals for the use of their data obtained for 
publication purposes only. Written informed consent was also taken from the subject whose picture is displayed in this article. Lips of the subject were cleaned with saline, air dried and then a red colored pencil Lipstick was applied with a single motion evenly on the lips. The cardboard bearing a 4 " $\times 10^{\prime \prime}$ strip of thin bond paper was then pressed to the subject's lips (Fig. 1). After obtaining the prints, the paper was labeled with name, age, sex and address of the individual and lip prints were studied with the help of a magnifying lens. Pencil lipsticks of the same color and make were used. To avoid infection, they were soaked in povidone-iodine and their tip was sharpened after each use.

\section{Examination of the Prints}

Photographs of the lips were transferred on a computer. The lip prints were divided into four quadrants (Fig. 2) in accordance with Saraswathi et al., ${ }^{9}$ Satyanarayana et al., ${ }^{10}$ Gupta et al., ${ }^{11}$ Prabhu et al. ${ }^{12}$ and Koneru et al. ${ }^{6}$ The same method of examination was repeated for the same subjects after one year. The findings revealed that with time there was no change in the lip print patterns.

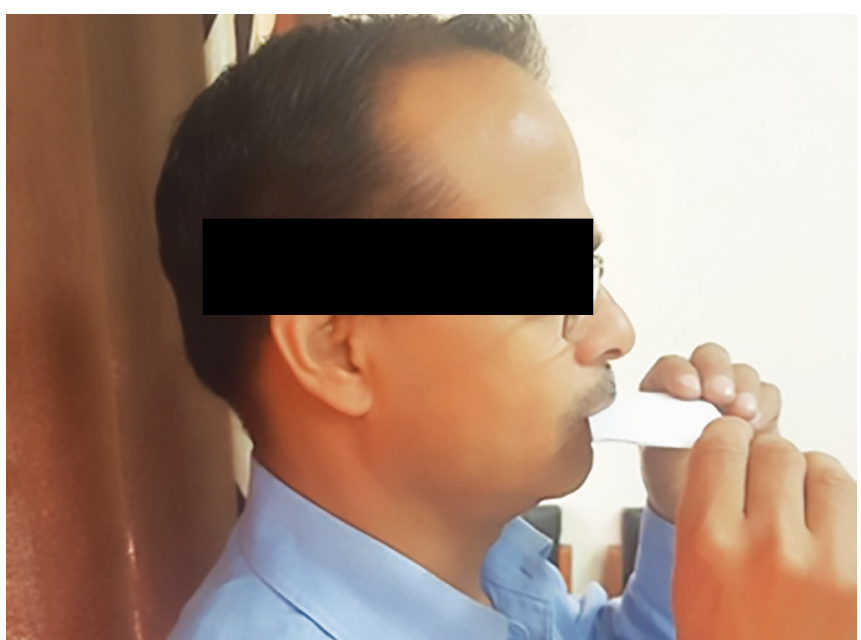

Fig. 1: Method of obtaining a lip print by pressing the folded paper between the lips

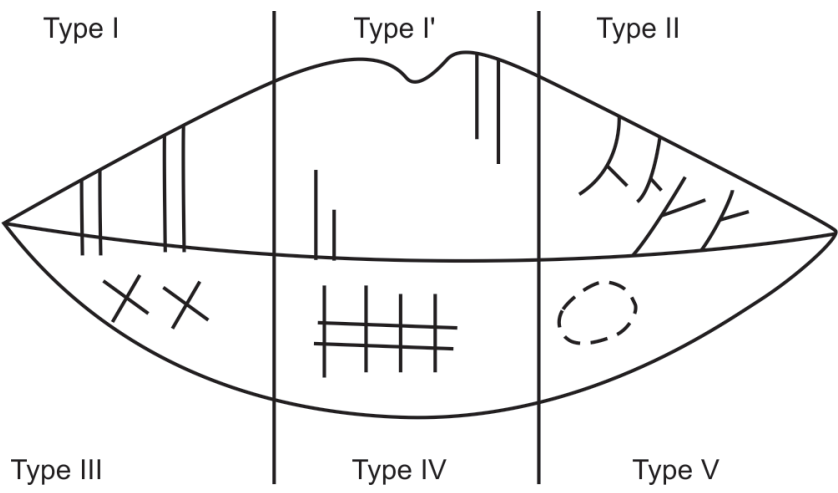

Fig. 2: Different lip pattern

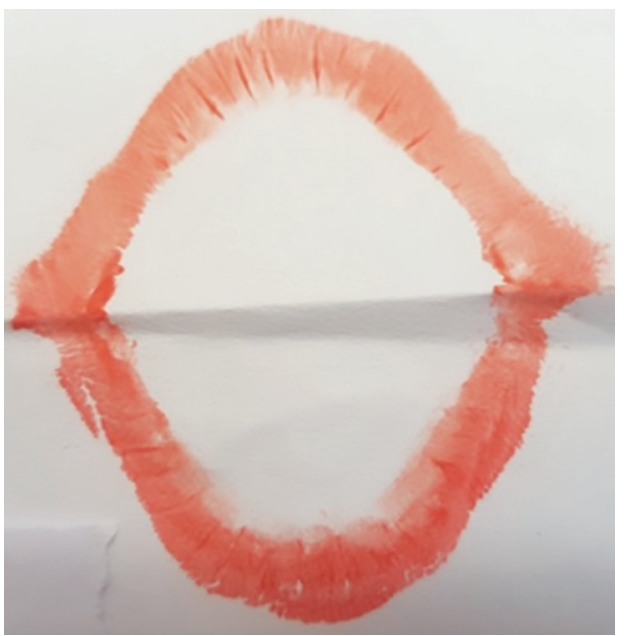

Fig. 3: Long and short vertical lip pattern (Types I and I')

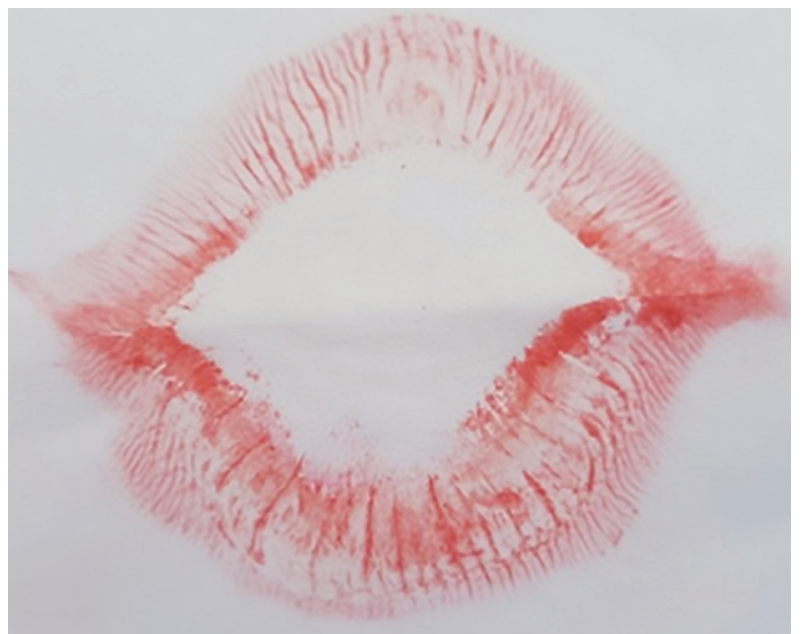

Fig. 4: Branching Y lip pattern (Type II)

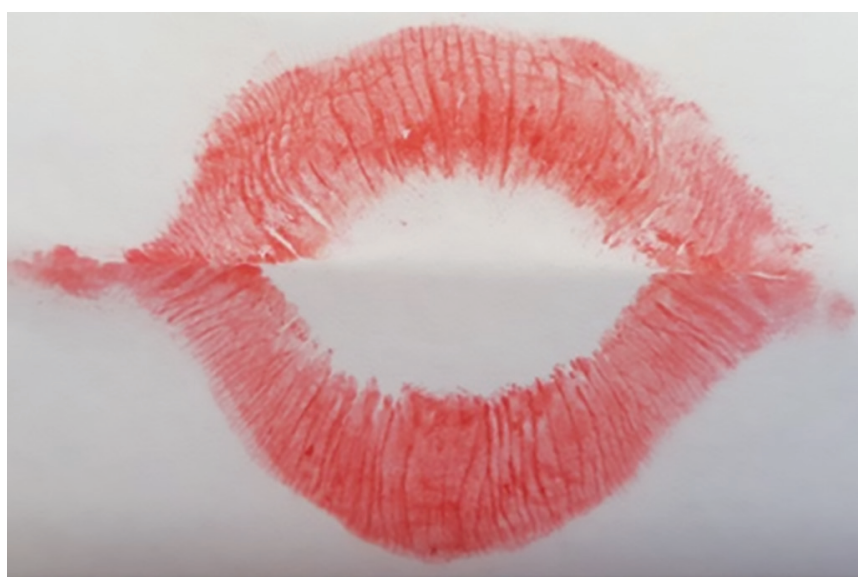

Fig. 5: Intersected criss-cross pattern (Type III)

\section{Classification of Lip Patterns}

We followed the classification of patterns on the lips proposed by Suzuki and Tsuchihashi: ${ }^{5}$

- Type I: Long vertical (Fig. 3)

- Type I': Short vertical (partial length) (Fig. 3)

- Type II: Branching Y shaped patter (Fig. 4)

- Type III: Intersected (criss-cross) x pattern (Fig. 5) 


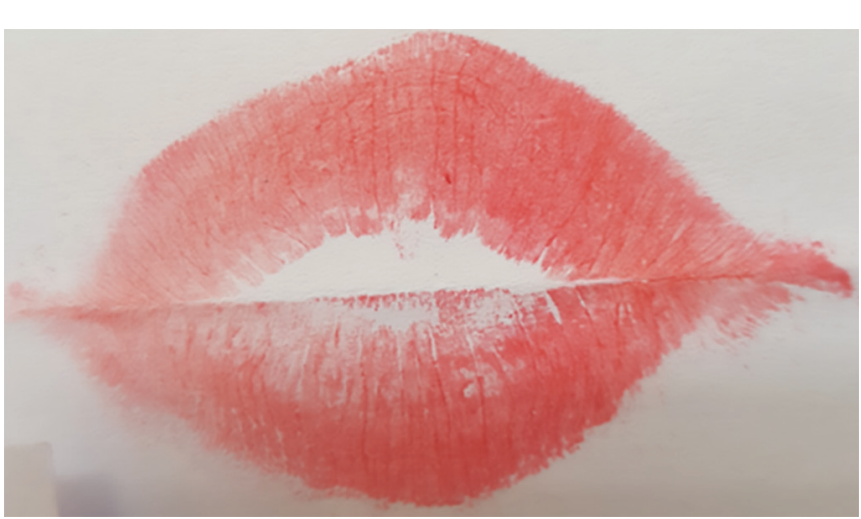

Fig. 6: Reticular fence pattern (Type IV)

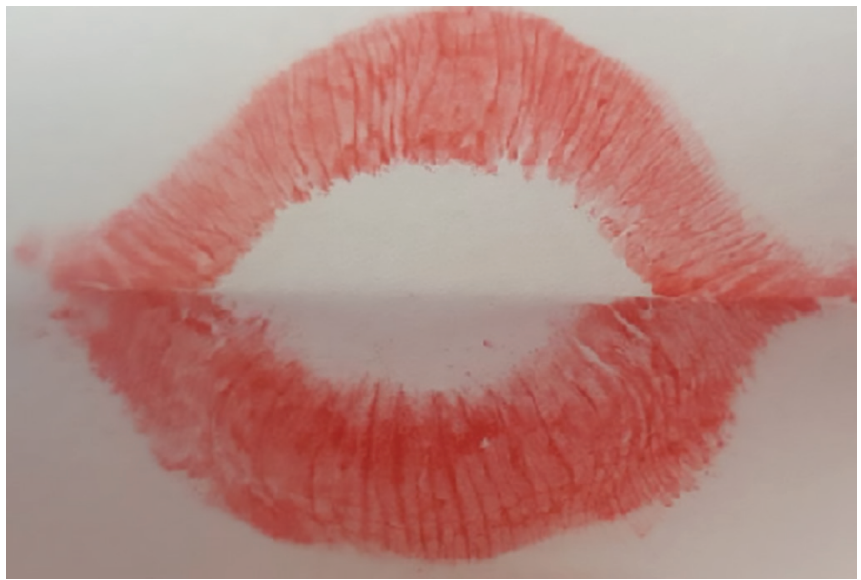

Fig. 7: Combination of two or more patterns

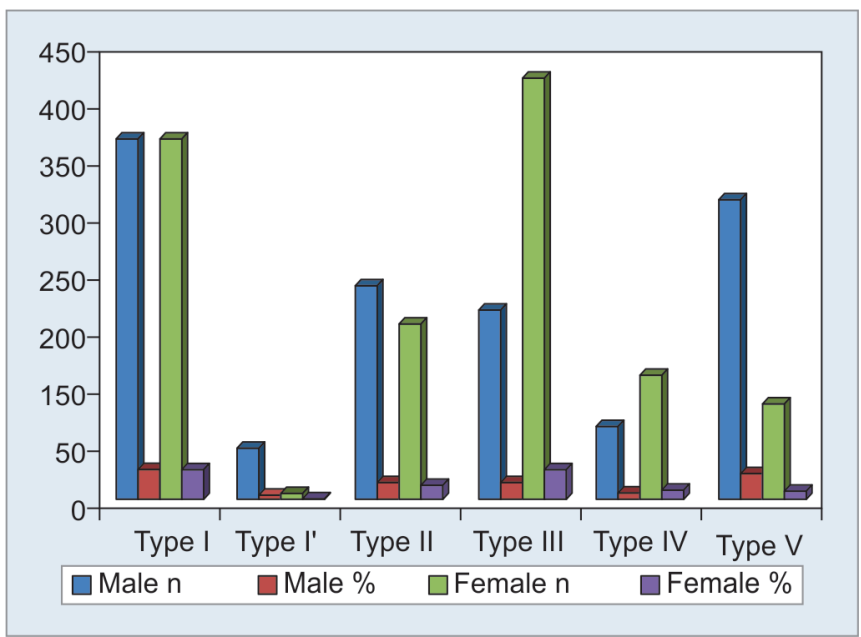

Fig. 8: Distribution of lip patterns in male and female subjects
- Type IV: Reticular, fence pattern (Fig. 6)

- Type V: Combination of two or more patterns (Fig. 7)

\section{RESULTS}

In male lip prints, the order of appearance of patterns were Type I $(30.33 \%)$ > Type V $(25.16 \%)>$ Type II $(17.91 \%)$ $>$ Type III $(15.91 \%)>$ Type IV $(6.33 \%)$ > Type I' $(4.33 \%)$ (least common) (Figs 3 to 8 and Table 1).

In female lip prints, the order of appearance of patterns were type III $(35.41 \%)>$ Type I $(30.66 \%)>$ Type II $(14.83 \%)>$ Type IV $(10.50 \%)>$ Type V $(8.16 \%)>$ Type I' $(0.41 \%)$ (least common) (Figs 3 to 8 and Table 1 ).

It was observed that:

1. Lip prints were unique to each individual.

2. There was no change in Lip prints on repeating the study after one year.

3. The common type of lip pattern and their percentage varied in our study population in males and females.

\section{DISCUSSION}

Lip printing can be a useful adjunct to fingerprinting for human identification. Domiaty et al. ${ }^{13}$ in their study on Saudi Arabian population stated thatlip prints are unique even among twins and family members. Ragab et al. ${ }^{14}$ and Costa et al. ${ }^{15}$ in their study on Egyptian and Portuguese population respectively further confirmed the ability to identify the individuals by means of lip prints.

In our study, no two lip prints showed precisely the same pattern which is in accordance with the study by Tsuchihashi ${ }^{16}$ on 1364 Japanese subjects $(757$ males and 607 females) aged between 20-30 years where no lip print showed the same pattern. Shivapathasundharam et $\mathrm{al}^{3}$ concluded that intersecting pattern was most common $(43.33 \%)$ and the reticular pattern was least commonly seen $(10.71 \%)$. Hirath ${ }^{17}$ noted branched pattern was the most common type in the upper lip while partial length pattern was most common in the lower lip. Bindal et al. ${ }^{18}$ in their study on 300 North Indians of 18 to 65 years of age found branching $\mathrm{Y}$ shaped pattern as most frequent pattern $(60.50 \%)$ in males, $(66.83 \%)$ in females and least observed pattern

Table 1: Distribution of patterns among male and females

\begin{tabular}{|c|c|c|c|c|}
\hline \multirow[b]{3}{*}{ Pattern } & \multicolumn{4}{|c|}{ Distribution of patterns } \\
\hline & \multicolumn{2}{|c|}{ Male (150 males) } & \multicolumn{2}{|c|}{ Female (150 females) } \\
\hline & n (1200 quadrants) & Percentage & n (1200 quadrants) & Percentage \\
\hline Long vertical (Type 1) & 364 & 30.33 & 368 & 30.66 \\
\hline Short vertical (Type 1') & 52 & 4.33 & 05 & 0.41 \\
\hline Branched (Type 11) & 215 & 17.91 & 178 & 14.83 \\
\hline Intersecting ( Type 111) & 191 & 15.91 & 425 & 35.41 \\
\hline Reticular (Type 1V) & 76 & $6 . .33$ & 126 & 10.50 \\
\hline Mixed/ Indefinite (Type V) & 302 & 25.16 & 98 & 8.16 \\
\hline Total & 1200 & 100 & 1200 & 100 \\
\hline
\end{tabular}


was crisscross pattern $(29.66 \%)$ in males, $(27 \%)$ in females. In our study, in males most frequent pattern was Long vertical $(30.33 \%)$, least observed pattern was short vertical (4.33\%). In females, most frequent pattern was intersecting $(35.41 \%)$ and the least observed pattern was short vertical $(0.41 \%)$ in accordance with the study of Kapoor and Badiye ${ }^{19}$ who concluded that in males, most frequent pattern was Long vertical (30.63\%), least observed pattern was short vertical (1.88\%). In females, the most frequent pattern was intersecting (35.75\%) and the least observed pattern was short vertical (0.25\%). Thus, like fingerprints, because of their uniqueness, lip prints can be utilized in court in personal identification of an individual positively.

\section{CONCLUSION}

Since lip prints are unique in every individual and do not change with time, so it can be used as an important tool in establishing identity, for finding lip pattern in both sexes and a powerful forensic tool in a criminal search to fetch the valuable information for individual identification during forensic investigations.

\section{LIMITATIONS}

The study can be elaborated to include a number of subjects as well study the lip prints on twins and nonbiological objects.

\section{REFERENCES}

1. Utsuno H, Kanoh T, Tadokoro O, Inoue K. Preliminary study of postmortem identification using lip prints. Forensic Sci Int 2005;149:129-132

2. Caldas IM, Magalhaes T, Afonso A. Establishing identity using cheiloscopy and palatoscopy. Forensic Sci Int 2007; 165 (1):1-9

3. Sivapathasundharam B, Prakash PA, Sivakumar G. Lip prints (cheiloscopy) Indian Dent Res 2001;12:234-237.
4. Shafer, Hine, Levy. Shafer's Textbook of Oral Pathology, sixth ed. Elsevier, Noida, India 2009, pp. 871-897.

5. Suzuki K, Tsuchihashi Y. A new attempt of personal identification by means of lip print. Can. Soc. Forensic Sci 1971; 4:154-158.

6. Koneru A, Surekha R, Nellithady GS, Vanishree M, Ramesh D, Patil RS. Comparison of lip prints in two different populations of India: reflections based on a preliminary examination J Forensic Dent Sci 2013;5:11-15.

7. Neville B, Damm D, Allen C, Bouquot J. Oral and maxillofacial pathology, 2nd ed. WB Saunders Company, Philadelphia, 2002 pp. 763-774.

8. Ball J. The current status of lip prints and their use for identification. J Forensic Odontostomatol 2002;20:43-46.

9. Saraswathi TR, Mishra G, Ranganathan K. Study of lip prints. J Forensic Dent Sci 2009;1:28-31.

10. Satyanarayana NK, Prabhu A, Nargund R. Forensic Odontology: cheiloscopy. Hong Kong Dent J. 2011;8:25-28.

11. Gupta S, Gupta K, Gupta OP. A Study of morphological patterns of lip prints in relation to gender of North Indian Population. J Oral Biol Craniofac Res 2011;1:12-16.

12. Prabhu RV, Dinkar A, Prabhu V. A study of lip print pattern in Goan dental students- a digital approach. J Forensic Legal Med 2012;19:390-395.

13. Domiatry MA, Gaidi SA, Elayat AA, Safwat MD, Galal SA. Morphological patterns of lip prints in Saudi Arabia at AlmadinahAllmonawarah province. Forensic Sci Int 2010;179:1-9.

14. Ragab AR, Dakroory SA, Rahman RH. Characteristic pattern of lip prints in Egyptian population sample at DakahliaGovernoratc. Int J Legal Med 2013;127:521-527.

15. Costa VA, Caldas IM. Morphologic patterns of lip prints in a Portuguese population: a Preliminary analysis. J Forensic Sci 2012;57:1318-1322.

16. Tsuchihashi Y. Studies on personal identification by means of lip prints. Forensic Sci 1974; 3:233-48.

17. Hirth L, Gottsche H, Goedde HW. Lipprints -variability and genetics. Humangenetik 1975;30:47-62.

18. Bindal U, Jethani SL, Mehrotra N, Rohtagi RK, Arora M, Sinha P. Lip prints as a method of identification in human being. J Anat Soc India 2009;58(2):152-155.

19. Kapoor N and Badiye A. A study of distribution, sex differences and stability of lip prints in an Indian Population. Saudi J of Bio Sci 2017;24:1149-1154. 